\title{
Operationalization of bandura's social learning theory to guide interprofessional simulation
}

\author{
Mary Jo Stanley, Sevaughn Banks, Wendy Matthew, Sherri Brown \\ California State University Stanislaus Turlock, CA, USA
}

Received: June 1, 2020

Accepted: July 2, 2020

Online Published: July 9, 2020

DOI: $10.5430 /$ jnep.v10n10p61

URL: https://doi.org/10.5430/jnep.v10n10p61

\begin{abstract}
Background and objective: In the clinical setting, health care professionals are expected to work in teams, yet, there is limited academic exposure to other allied health students and little preparation is done in traditional classrooms to practice with other allied health students. As health professionals work in an environment influenced by social interaction, interprofessional simulation (IPS) instruction may lack necessary frameworks that support professional practice. To promote collaborative learning in IPS that takes into account real interprofessional clinical situations, Bandura's social learning theory was used as the guiding framework for this pilot simulation study.

Methods: Conventional content analysis, as used in study designs to describe a phenomenon, allowed for the flow of categories to be derived from standardized debriefing sessions with nursing and social work students $(\mathrm{N}=24)$.

Results: Qualitative data identified three themes capturing students' voices: effective and efficient patient care, team appreciation, and early implementation of simulation.

Discussion and conclusions: Outcomes of this pilot study support the integration of a guiding framework in designing IPS for nursing and social work education that takes into account the social nature of the clinical environment through observed action and replicated behavior for requisite interprofessional skills for clinical practice.
\end{abstract}

Key Words: Interprofessional simulation, Interprofessional education, Interprofessional collaboration, Social learning theory

\section{INTRODUCTION AND BACKGROUND}

Health care education, typically done in silos and with limited appreciation for the breadth and scope of other health professions, needs greater integration in social work and nursing curricular offerings. A collective approach to teaching students about patient care breeds collaboration in the workforce. ${ }^{[1-4]}$ For nursing and social workers, understanding of other health professionals' roles takes place once students are hired into clinical positions post-graduation and after direct interprofessional contact. The Institute of Medicine ${ }^{[5]}$ and the Council on Social Work Education ${ }^{[6]}$ calls for increased interprofessional education including integration of collabo- rative practice in educational curriculum. While nursing has made strides in this area, further understanding of roles is needed. ${ }^{[7]}$ In the field of social work, limited acknowledgement of simulation in pedagogical practices is noted. ${ }^{[4,8,9]}$

Interprofessional practice is a key component for effective communication, improving patient care, increasing understanding between professions, reducing fragmented care, and improving patient safety. ${ }^{[5,10-15]}$ Inclusion of simulation enhanced interprofessional education (IPE) or interprofessional simulation (IPS) can allow health professionals to see the health care team's collaborative impact on patient care. ${ }^{[7,16]}$ In the clinical setting, health care professionals are expected

*Correspondence: Mary Jo Stanley; Email: mstanley@csustan.edu; Address: California State University Stanislaus Turlock, CA, USA. 
to work in teams, yet, there is limited academic exposure to other allied health students and little preparation is done in traditional classrooms to practice with other allied health students; a gap in curriculum that supports an interprofessional approach exists..$^{77,12,13,16]}$

IPS as a pedagogical tool in the academic setting supports cooperative and collaborative practice allowing students to develop their skills in a safe environment; yet developing, writing, and re-designing simulations to accommodate interprofessional roles can be challenging. ${ }^{[17]}$ Kutzin $^{[18]}$ identifies the need to provide appropriate scenarios for each discipline while supporting the unique competencies of each profession. Scenarios often used for IPS training may actually overwhelm students as teamwork and communication may be overlooked due to a focus on basic skills that have not been mastered. ${ }^{[18]}$ IPS that is designed to foster interprofessional skills provides health professionals practice in mastery for real "interprofessional clinical situations". ${ }^{[19]}$ As health professionals work in an environment influenced by social interaction, IPS instruction may lack necessary frameworks that support professional practice. ${ }^{[19]}$

When creating IPS learning environments for allied health students, instructors may need to consider learning theories within a social context. Several theories explain social interaction and learning such as Bandura's Social Learning Theory, ${ }^{[20]}$ Vygotsky's Sociocultural Theory, ${ }^{[21]}$ and Piaget's Theory of Cognitive Development. ${ }^{[22]}$ Vygotsky provides a strong framework for social learning with an emphasis on a "more knowledgeable other". ${ }^{[21]}$ The purpose of this study was not to promote hierarchical practices, but to support a team-base structure, with both nursing and social work sharing information and learning form one another. While Piaget 's theory provides learning and growth in relation to individual maturation, ${ }^{[22]}$ the purpose of this study was to support a collaborative approach to patient care. Banduras Social Learning Theory provides the best fit for this pilot study as it allows for peer mentorship and team-based mindset for learning. ${ }^{[20]}$

Research that demonstrates effective teamwork as part of the curricular design and aligned with a guiding framework is needed. ${ }^{[7,10,11,14,23,24]}$ To support this gap in the literature, social work and nursing departments from one university sought to provide a collaborative pilot simulation experience using Bandura's social learning theory as the guiding framework for the IPS design.

\section{Theoretical framework}

Albert Bandura's social learning theory 20 was used as the guiding framework for student learning in this simulation.
Social learning theory (SLT) has four learner-centric phases: attention, retention, reproduction, and motivation; these four phases drove creation of the IPS study and aligned with student learning outcomes for both nursing and social work and implementation of them in simulation (Appendix A).

The attention phase requires learner observation and focus on the task. Students pay close attention to their surroundings, what is articulated by patients and peers, and sensitivity to demonstrating core professional skills in simulation, allowing them opportunity to focus on peer learning and client interactions. The attention phase sets the foundation for a team-based approach in patient care. This kind of contextual learning reinforces students' understanding of concepts they read about and discuss in class. Nursing and social work students collaboratively interact with the patient and observe each respective discipline's role in real time allowing them to witness the use of evidence obtained from multiple sources that support patient centered care.

Retention, the second phase, involves storage and retrieval of newly acquired information. Nursing and social work students apply previous knowledge from readings, lectures, and clinical experiences to provide patient centered care. Nursing and social work students demonstrate knowledge engagement, communication, and assessment, which is mostly theoretical and hypothetical until simulation. This allows both sets of students to be acutely aware of their converging roles and how their individual and collective interactions in practice exemplifies the best team-based care.

Reproduction, the third phase, focuses on learner performance guided by memory of observed actions. When nursing and social work students' care for patients in the clinical environment, they are able to evaluate their successful team-based strategies and replicate their practice behavior in real world settings because they have evidence that what worked in the past will be successful in the future. Students operationalize this evidence through client engagement, interdisciplinary collaboration, articulation of appropriate patient referrals, and recommendations based upon each patients' unique needs and abilities. This approach leads to the indelible practice of team-based patient care, transferable to the workforce post-graduation.

The final phase, motivation, focuses on learner impetus to repeat the observed behavior. Nursing and social work students develop increased competence and confidence leading to internalized assurance and a sense of personal agency they carry with them into a variety of work settings. Students realize they are not working in silos, but rather are part of a larger team focused on the best outcomes for the patient. Learners are also more likely to demonstrate behaviors that are valued 
by patients, peers, and instructors. Once students value the purpose and function of simulation, they become empowered by the experience, are motivated to inform others about their positive experience, and are willing to participate in additional simulation scenarios. A simulation culture provides the type of academic environment that increases teamwork, interprofessional practice, and improves patient care.

\section{Methods}

\subsection{Simulation}

Students provided care to a 24-year-old female patient who experienced heart palpitations, epigastric pain, muscle weakness, and a near-syncopal episode in a simulated hospital setting. Social work and nursing students each performed discipline specific assessment, as well as management of care for a patient experiencing dysrhythmias, electrolyte imbalance, and eating disorder. One social work student was paired with two nursing students and each team spent 15 minutes performing medical and psychosocial tasks. Nursing students were the first to initiate care with the patient; faculty provided limited instruction regarding hand-off or communication to encourage authentic engagement between the two professional groups. A collaborative 30-minute debriefing session with both sets of students immediately followed the simulation cycle. Scenarios consisted of four simultaneous simulations preceding a debriefing session of 12 students. Use of Bandura ${ }^{[20]}$ as a guiding framework for course objectives and implications for simulation can be seen in Appendix A.

\subsection{Procedures and data collection}

Nursing and social work faculty conducted a collaborative simulation pilot study between nursing and social work students, using both high fidelity (HF) manikins and standardized patients (SPs) in simulation. In an effort to increase student exposure to other allied health fields both social work and nursing departments from a small state funded university on the west coast took efforts to collaborate. Aligning course objectives for both disciplines into one simulation that meet student outcomes was a collaborative effort between three nursing faculty (includes simulation coordinator), two social work faculty, and one simulation technician within the two departments. Nursing and social work faculty along with the simulation technician ran all eight simulations. Two faculty, who were part of the research team, were responsible for the debriefings. Participants consisted of a convenience sample of eight social work (from a possible 16) and 16 nursing students (from a possible 30) as part of a clinical course. Entry-level Master of Social Work (MSW) students in their first semester of a four-semester program and senior Bachelor of Science (BSN) pre-licensure nursing students in their final course (of a six-semester program), agreed to participate in the study. All participants were 21 years of age or older and consented to participate in the study. No class grade was associated with student performance in simulation. Students were not required to participate in the simulation but were encouraged; the simulation was in addition to their clinical experience. University Institutional Review Board approval was obtained for the study.

A content analysis design was used to derive meaning from two debriefing sessions completed with both social work and nursing students $(\mathrm{N}=24)$. Debriefing sessions were audio recorded and transcribed verbatim. Conventional content analysis describes a phenomenon of interest where categories and names to define the categories were derived from the data. ${ }^{[25]}$ Data was collected through open-ended questions where codes from text were sorted into categories, and group codes became meaningful clusters. Seven debriefing questions (such as, "How did you feel about communication between nursing and social work?" and "Tell me more about your perception of IPS?") allowed researchers to organize the data into twelve defined subcategories where three dominant themes were identified: Effective and Efficient Patient Care, Team Appreciation, and Early Implementation. Similar to other content analysis approaches, ${ }^{[25]}$ relevant theories as they align to the results are discussed; qualitative analysis as it relates to Bandura's theory ${ }^{[20]}$ can be found in the discussion section. Procedural rigor was followed using peer review, member checking, audit trail, and prolonged engagement with the data; data saturation was obtained. ${ }^{[26]}$ In addition to the open-ended questions, the Pearls Healthcare Debriefing Tool was used to support standardized debriefing. ${ }^{[27]}$

\section{RESUlTS}

Aggregated demographic data was collected for all 24 students. Social work and nursing students varied in age, ranging from 20-28. The social work mean age was 25 and the nursing mean age was 24 , four male students participated (social work $\mathrm{N}=1$ and nursing $\mathrm{N}=3$ ), and 20 female students participated in the study (social work $\mathrm{N}=7$ and nursing $\mathrm{N}$ =13). Three students self-identified as Black (social work $\mathrm{N}=1$ and nursing $\mathrm{N}=2$ ), nine as Latino (social work $\mathrm{N}=4$ and nursing $\mathrm{N}=5$ ), seven as Asian (social work $\mathrm{N}=1$ and nursing $\mathrm{N}=6$ ), and five as Caucasian (social work $\mathrm{N}=2$ and nursing $\mathrm{N}=3$ ).

\subsection{Qualitative data}

Qualitative data collected during two debriefing sessions answered the research question: What are nursing and social work students' perceptions regarding interprofessional col- 
laboration in simulation? Data was synthesized and three themes emerged that captured students' voices related to Effective and Efficient Patient Care, Team Appreciation, and Early Implementation.

\section{Effective and efficient patient care}

Students were focused only on their roles and did not see the whole picture related to patient care. One nursing student said, while acknowledging the limitations of her professional role, "... making sure the patient is psychologically safe too rather than just physically safe" was an important revelation echoed by other students learning how to share space in a clinical setting with an allied professional. Psychosocial components of care were not addressed, one nursing student indicated, "... somewhere along the way, I would have asked about self-harm or suicide, but I didn't get to that yet." All students expressed difficulty in completing the tasks based on limited time, one social work student said, "I find I have only 15 minutes and need to complete this form." Students perceived having adequate time to complete their duties equated to a safer patient experience. "It's not enough time to really express what's going on with the patient" and "I felt like I was rushing the client." Nursing students were focused on tasks "We got patient labs" and "We checked vital signs, blood pressure, oxygen" while social work students worked to complete their intake form while juggling the patient's psycho-social needs, "I have a patient crying here, I wasn't sure what I was supposed to do. It was difficult." In fact, some social work and nursing students did not think to interact with the other health professional. A nursing student stated, "We were focused on our skills and really didn't have the thought of like, 'oh, I can refer this person'." Some students indicated that communication between professions might support good patient care. One nursing student said, "[The patient] has all these factors going on in her life, kind of a road map, I was already thinking in my mind, how I'm going to assist this patient or where I need to direct her" and "We have to investigate more."

\subsection{Team appreciation}

Students realized the value of the simulation experience, "It truly feels good to see that you can work together to help patients. It is not just on your plate; you can get help by working together to help the patient. It was nice." Some students appreciated having another professional in the room to provide a second pair of eyes and a professional opinion. One social work student said, "I thought it was really cool for us to participate in interdisciplinary teams because, once we get to the hospital, we're asking each other, what do you need?" All students articulated benefits of a team approach to care, and one nursing student recognized, "Sometimes [patients] physical symptoms cause mental symptoms and vice versa. So, working as a team and collaborating is best for the patients." Students overwhelmingly felt simulation contributed to their learning about teams, "It was interesting to see the whole team working together. I felt like the nurse I participated with did a good job of telling me what was going on with the patient's nutrition." Social work students expressed a team-based approach to care facilitated efficiency with patient care, "It can be very time saving if we collaborate with the nurses and doctors to get as much information as possible". Both social work and nursing students felt they had not had enough exposure to collaborative learning environment, "We really haven't been taught too much" and "Knowing how to use our resources more" was stated by several nursing students. Participants overwhelming agreed that the collaborative experience was "Helpful for professional development. I would have this in our curriculum."

\subsection{Early implementation}

Students believed collaborative interprofessional simulation should be implemented early as it forced students to think about a team-based approach to patient care. One student said, "I think implementing this early on along with our curriculum, doing collaboration between social work and nursing, would really benefit everyone. For us nursing students, we tend to forget the psycho-social part and that there's a human without a diagnosis." Social work students identified the benefits of working in a simulated environment to improve their skills and communication prior to direct patient care, "This was good practice for my social skills and cueing for communication. I remember learning about therapeutic communication, but this was more than remembering, this allowed me to utilize." Students acknowledged having an authentic practice environment was crucial to learning; one nursing students said, "I was trying to connect with the patient when I noticed she was crying; I didn't know what to do," and a social work student indicated "It forces you to work better with a person; you don't want to act in a way that is insensitive or hurts that person's feelings." Student identified that IPS offered an opportunity for improved engagement realizing the value that this practice environment offered, "If you walk in saying this can be a real scenario in my life and in another person's, this can affect somebody later" and "I've done role playing in the classroom before, but it just felt more real with nursing students in the room." Early exposure to IPS has the potential to reinforce good habits and practices; several students expressed the collaborative approach to simulation as their best experience to date. 


\subsection{Lessons learned}

This collaborative simulation experience between two allied health disciplines took much planning and preparation. It Is important to define duties early on and learn each disciplines' role. Just like the outcomes for the students in this study, faculty do not always understand each other's' profession; regular communication is essential. While unintended events are not anticipated, plan for the unexpected. Pick a backup day for simulation should unforeseen events occur.

\subsection{Limitations}

Limitations of the study include a small sample size, convenience sampling, inclusion of only two interprofessional groups, and use of a single site to conduct the study.

\section{Discussion}

Nursing and social work frequently engage professionally after obtaining their degrees, yet the nursing and social work educators do not commonly collaborate or combine educational instruction within their curriculum. Kutzin ${ }^{[18]}$ notes that IPS instruction should be designed to support interprofessional skills such as teamwork and collaboration rather than a focus on each discipline's specific skills. For this study Bandura's social learning theory ${ }^{[20]}$ was used as a guide for collaborative instructional practices in an attempt to address this silo-based educational approach. In addition, findings from the conventional content analysis approach, ${ }^{[25]}$ as it relates to Bandura's theory ${ }^{[20]}$ are discussed.

As noted in student's comments through the effective and efficient patient care theme, students perceived good care was about getting their work completed, but quickly realized that the care required was more complex than just their own tasks. By observing what the other health professional was doing, students saw a larger picture of patient care. Similar to the attention phase of Bandura's social learning theory, ${ }^{[20]}$ the student is observing and taking in the situation, understanding the distinction of each health care providers' role in the ultimate outcome of the patient. Students' comments indicated value in working together for the benefit of the patient, developing a team-based mindset. Similar to the work from Costello, ${ }^{[11]}$ confidence in discipline specific roles can occur when students feel they can influence patient outcomes and experience the comfort of working as a team.

Outcomes from the study support the use of IPS as a collaborative educational tool to promote communication, teambased engagement, and early exposure to simulation as a part of students' academic learning experience. Student feedback was overwhelmingly positive as they discussed cultivating a teamwork mind set and improved understanding between the two professions as noted in the team appreciation theme as a benefit of a team approach to care. Similar to the retention phase of Bandura, ${ }^{[20]}$ students saw value in a team approach as both parties bring a broader context to the situation and information can be shared. Students learn from their previous knowledge but build new knowledge specific to these collaborative experiences. Consistent with previous studies, students expressed an increase in their own understanding of interprofessional collaboration, improved communication, and support of one another as they now start to understand the convergence of their roles in the bigger picture of patient care. $^{[10,11]}$

Students in this study stated their desire to continue using IPS and suggested increasing access to this strategy in the educational curriculum. The theme, early implementation, established that students comprehend collaborative simulation as a valuable learning tool to foster confidence in their roles as nurses and social workers. As noted in Bandura's reproductive phase, ${ }^{[20]}$ while debriefing, students could reflect on and evaluate the strategies that worked well in the simulation which can then be used to inform future practice. Similar to the work of Peterson, ${ }^{[28]}$ students gained insight into how collaborative practice with allied peers can influence patient care. Students quickly saw the value in collaborative simulation and as noted through Bandura's motivational phase ${ }^{[20]}$ students indicated the need for more IPS and earlier collaboration within their educational training.

Kiesewetter ${ }^{[19]}$ notes the absence of theoretical frameworks in the design of IPE for collaborative learning in the literature. In preparing health professionals for interprofessional practice, appropriate frameworks must be applied that foster competencies for interprofessional care. Social Learning Theory ${ }^{[20]}$ takes into account the social nature of clinical environments while increasing confidence and competence through observed action and replicated behavior to inform practice. Further understanding of the social environment in which nursing and social work students will be working is imperative. Educational pedagogies that acknowledge collaborative experiences need to be implemented early on in students' training so as to guide and reinforce indelible practices.

\section{Conclusion}

The World Health Organization ${ }^{[29]}$ supports a "practice-ready workforce" where health workers are prepared and have the skills to work in collaborative teams. Educational instruction should apply guiding frameworks that take into account the social nature of the health care environment proving experiences that replicate real practice. Collaborative care experiences that provide observed action and replicated behavior through simulated experiences allow student to gain 
confidence and competence in working as part of a larger team. Outcomes of this pilot study support the integration of a guiding framework in designing IPS for both nursing and social work education where students can apply neces- sary interprofessional skills they will need in clinical work settings.

\section{CONFlicts of INTEREST Disclosure}

The authors declare that there is no conflict of interest.

\section{REFERENCES}

[1] Blacker S, Head BA, Jones BL, et al. Advancing Hospice and Palliative Care Social Work Leadership in Interprofessional Education and Practice. Journal of Social Work In End-Of-Life \& Palliative Care. 2016; 12(4): 316-330. PMid:27938025 https: //doi.org/10.1080/15524256.2016.1247771

[2] O'Rourke J, Horsley TL, Doolen J, et al. Integrative Review of Interprofessional Simulation in Nursing Practice. The Journal of Continuing Education in Nursing. 2018; 49(2): 91-96. PMid:29381173 https://doi.org/10.3928/00220124-20180116-09

[3] West A, Miller S, Leitch J. Professional Socialization and Attitudes Towards Interprofessional Collaboration Among Graduate Social Work and Health Professions. Advances in Social Work. 2016; 17(2): 134-150. https://doi.org/10.18060/19809

[4] Zaldy T, Damron-Rodriguez J, Cadogan M, et al. Team-based interprofessional competency training for dementia screening and management. Journal of the American Geriatrics Society. 2017; 65(1): $207-$ 211. PMid:27902840 https://doi.org/10.1111/jgs. 14540

[5] Institute of Medicine (IOM). Framework for action on interprofessional education and collaborative practice. 2010. Available from: http://apps. who.int/iris/bitstream/handle/10665/701 85/WHO_HRH_HPN_10.3_eng.pdf ; jsessionid=62A6B914D62 42E977726DC29AA3AEF2E? sequence $=1$

[6] Council on Social Work Education (CSWE). Educational policy and accreditation standards (EPAS) for baccalaureate and masters of social work programs. Available from: https://www.cswe.org /getattachment/Accreditation/Accreditation-Process /2015-EPAS/2015EPAS_Web_FINAL.pdf .aspx

[7] Horsley T, O'Rourke J, Mariani B, et al. An integrative review of interprofessional simulation in nursing education. Clinical Simulation in Nursing. 2018; 22: 5-12. https://doi.org/10.1016/j.ecns .2018 .06 .001

[8] Addy C, Browne T, Blake E, et al. Enhancing interprofessional education: Integrating public health and social work perspectives. American Journal of Public Health. 2015; 105: S106-S108. PMid:25706002 https://doi.org/10.2105/AJPH. 2014.302502

[9] Schaefer J, Larking S. Interprofessional education in undergraduate social work education. The Journal of Baccalaureate Social Work 2015; 20(1): 179-188. https://doi.org/10.18084/1084-721 9.20.1.179

[10] Boscart V, Heckman G, Huson K, et al. Implementation of an interprofessional communication and collaboration intervention to improve care capacity for heart failure management in long-term care. Journal of Interprofessional Care. 2017; 31(5): 583-592. PMid:28876202 https://doi.org/10.1080/13561820.2017.1340875

[11] Costello M, Prelack K, Faller J, et al. Student experiences of interprofessional simulation: Findings from a qualitative study. Journal of Interprofessional Care. 2018; 32(1): 95-97. PMid:28862486 https://doi.org/10.1080/13561820.2017.1356810

[12] King J, Beanlands S, Fiset V, et al. Using interprofessional simulation to improve collaborative competences for nursing, phys- iotherapy, and respiratory therapy students. Journal of Interprofessional Care. 2016; 30(5): 599-605. PMid:27340933 https: //doi.org/10.1080/13561820.2016.1189887

[13] Murphy J, Nimmagadda J. Partnering to provide simulated learning to address interprofessional education collaborative core competencies. Journal of Interprofessional Care. 2015; 29(3): 258259. PMid:25076021 https://doi.org/10.3109/13561820.2 014.942779

[14] Wilcox J, Miller-Cribbs J, Kientz E, et al. Impact of simulation on students' attitudes about interprofessional collaboration. Clinical Simulation in Nursing. 2017; 13(8): 390-397. https://doi.org/10 $.1016 / j$.ecns. 2017.04.004

[15] Zhang C, Miller C, Volkman K, et al. Evaluation of the team performance observation tool with targeted behavioral markers in simulation-based interprofessional education. Journal of Interprofessional Care. 2015; 29(3): 202-208. PMid:25421454 https: //doi.org/10.3109/13561820.2014.982789

[16] International Association for Clinical Simulation and Learning [INACSL]. INACSL standards of best practice: Simulation. Simulationenhanced interprofessional education (SIM-IPE). Clinical Simulation in Nursing. 2016; 12: S34-S38. https://doi.org/10.1016/j . ecns. 2016.09.011

[17] Stephenson E, Poore J, Byrne B, et al. Interprofessional educator development course for simulation. Journal of Continuing Education in Nursing. 2019; 50(10): 463-468. PMid:31556962 https: //doi.org/10.3928/00220124-20190917-08

[18] Kutzin J. Escape the room: Innovative approaches to interprofessional education. Journal of Nursing Education. 2019; 58(8): 474480. PMid:31373669 https://doi .org/10.3928/01484834-2 0190719-07

[19] Kiesewetter J, Kollar I, Fernandez N, et al. Crossing boundaries in interprofessional education: A call for instructional integration of two script concepts. Journal of Interprofessional Care. 2016; 30(5): 689692. PMid:27309966 https://doi.org/10.1080/13561820.2 016.1184238

[20] Bandura AJ. Social learning theory. Englewood Cliffs, NJ. 1977.

[21] McLeod S. Lev Vygotsky's Sociocultural Theory. Simply Psychology. 2018. Available from: https://www . simplypsychology.o $\mathrm{rg} /$ vygotsky.html

[22] Piaget J. Piaget's Theory. In: Inhelder B., Chipman H.H., Zwingmann C. (eds) Piaget and His School. Springer Study Edition. Springer, Berlin, Heidelberg. 1976.

[23] Banks S, Stanley M, Brown S, et al. Simulation-based interprofessional education: A nursing and social work collaboration. Journal of Nursing Education. 2019; 58(2): 110-113. PMid:30721312 https://doi.org/10.3928/01484834-20190122-09

[24] Fulmer T. Effective interdisciplinary teams: Do we really know how to build them? Journal of the American Society on Aging. 2016; 40(1): 64-70.

[25] Hsieh H, Shannon S. Three approaches to qualitative content analysis. Qualitative Health Research. 2005; 15(9): 1277-1288. 
PMid:16204405 https://doi.org/10.1177/10497323052766 87

[26] Lincoln YS, Guba EG. Naturalistic inquiry. Newbury Park, CA. 1985.

[27] Eppich W, Cheng A. Promoting excellence and reflective learning in simulation (PEARLS): Development and rationale for a blended approach to health care simulation debriefing. Simulation in Healthcare. 2015; 10(2): 106-115. PMid:25710312 https://doi.org/ 10.1097/SIH.0000000000000072

[28] Peterson D, Brown M, Wingo N, et al. Exploring hidden curriculum in an interprofessional intensive care unit simulation. Clinical Simulation in Nursing. 2018; 22: 22-25. https ://doi.org/10.1016/ j.ecns.2018.07.001

[29] World Health Organization. Framework for action on interprofessional education \& collaborative practice. Geneva, Switzerland: WHO Department of Human Resources for Health. 2010. Available from: http://apps.who.int/iris/bitstream/handle/106 65/70185/WHO_HRH_HPN_10.3_eng.pdf ; j sessionid=B2083 90A7AE78EA4C6103F28A8A96247? sequence $=1$ 